\title{
Aspectos ecológicos e fitogeográficos de remanescentes florestais na paisagem urbana de Cachoeira do Sul/RS
}

\author{
Ecological and phytogeographical aspects of forest remnants in \\ the urban landscape of Cachoeira do Sul / RS \\ Diogo de Souza Lindenmaier ${ }^{1}$, Bernardo Sayão Penna e Souza ${ }^{2}$ \\ ${ }^{1}$ Mestrando do PPG-GEO - UFSM , Santa Maria, Rio Grande do Sul, Brasil \\ ${ }^{2}$ Professor Doutor no PPG-Geociências - UFSM, Santa Maria, Rio Grande do Sul, Brasil
}

\begin{abstract}
Resumo
O presente estudo analisou a presença de remanescentes florestais no espaço urbano de Cachoeira do Sul/RS, com objetivo de identificar as espécies arbóreas presentes nas áreas, estimar a diversidade, o estádio sucessional, as estratégias de dispersão e as relações fitogeográficas entre espécies e indivíduos que compõem os fragmentos. Os remanescentes florestais foram identificados e mapeados com auxílio de sensoriamento remoto. No interior das florestas, foram demarcadas parcelas de $10 \mathrm{~m} \times 10 \mathrm{~m}$, onde todos os indivíduos arbóreos com perímetro mínimo de $10 \mathrm{~cm}$ à altura do peito foram amostrados. Foram identificadas 82 espécies arbóreas distribuídas em 34 famílias botânicas. Houve predominância de espécies e indivíduos com características secundárias iniciais, bem como alta frequência de espécies exóticas. Os fragmentos apresentaram ainda considerável índice de diversidade, predominância de síndrome de dispersão zoocórica, sendo a maioria das espécies e indivíduos de ampla distribuição nas formações florestais do Sul do Brasil.
\end{abstract}

\begin{abstract}
The present study examined the presence of remaining forest within the city of Cachoeira do Sul/RS, aiming to identify the tree species present in the areas, estimating diversity, successional stage, dispersion strategies and phytogeographical relationships between species and individuals composing the fragments. The forest remnants were identified and mapped with the aid of remote sensing. Were demarcated within forest plots of $10 \mathrm{~m} \times 10 \mathrm{~m}$ where all trees with minimum perimeter of $10 \mathrm{~cm}$ to $1.2 \mathrm{~m}$ of soil were sampled. We identified 82 tree species distributed in 34 plant families. There was a predominance of species and individuals with early secondary characteristics as well as high frequency of exotic elements. The fragments also showed considerable diversity index, dominance of dispersion syndrome zoochorous, the majority of species and individuals of widely distributed in forest formations of southern Brazil.
\end{abstract}




\section{Introdução}

Em 2011, a humanidade atingiu a marca histórica de sete bilhões de pessoas, dentre as quais, 50\% vivem em cidades (UFNPA, 2011). No Brasil, esse número chega a mais de $84 \%$ da população.

Diante dessa nova realidade, o tema da qualidade ambiental urbana ganha atenção de pesquisadores brasileiros e de todo mundo, uma vez que a melhoria da qualidade de vida nas cidades depende diretamente da qualidade ambiental (PUGLIELLI, 2008).

As cidades podem ser pensadas como paisagens onde diferentes elementos interagem de forma sistêmica, influenciando a conformação do mosaico urbano. Sendo assim, a ação do homem, definida aqui como elemento antrópico, tem influência preponderante sobre os demais componentes do sistema urbano, transformando as cidades em espaços altamente complexos e, completamente distintos dos ambientes naturais (CHRISTOFOLETTI, 1999).

A vegetação é um dos elementos mais importantes no arranjo fisionômico de uma paisagem e diversos estudos têm associado qualidade de vida nas cidades à presença de vegetação (PUGLIELLI, 2008). A organização do elemento vegetativo arbóreo no desenho urbano está relacionada, especialmente, com suas funções de lazer, estética e ecológica.

No Sul do Brasil, diversas pesquisas sobre vegetação urbana abordando aspectos qualitativos e quantitativos têm sido realizadas, tais como índices de cobertura vegetal, qualidade ambiental urbana e investigações de cunho ecológico. Entretanto, estudos interdisciplinares sobre a estrutura da vegetação urbana e as políticas de planejamento ainda são escassos. Deste modo, pesquisas e políticas públicas sobre $\mathrm{o}$ verde urbano merecem maior atenção, tendo em vista o acelerado crescimento do setor imobiliário que, aparentemente, não contempla essa demanda, cada vez mais necessária à melhoria das cidades (LIMA NETO et al., 2010).

De acordo com sua distribuição na paisagem urbana, a vegetação pode ser classificada em: áreas verdes, correspondente às praças, parques e jardins; arborização viária, árvores presentes nos passeios, canteiros e rotatórias; vegetação de áreas privadas, presentes em residências, condomínios e áreas industriais; e florestas urbanas, que correspondem os remanescentes florestais dentro do espaço urbano. Esta classificação é uma adaptação formulada a partir dos trabalhos de Gêiser et al., (1976); Lima et al., (1994); Demattê, (1997); Badiru et al., (2005); Magalhães, (2006); Caporusso e Matias (2008) e Benini (2009).

Contudo, Grey e Deneke (1978, apud BADIRU et al., 2005), definem as florestas urbanas como toda vegetação integrada à cidade, o que corresponde a todos os espaços arborizados que servem à população urbana. A floresta urbana seria um conjunto do espaço combinado com a vegetação, cujo manejo deve ser feito de forma integrada aos ambientes da cidade. Já Magalhães (2006) afirma que florestas correspondem às áreas maiores e contíguas, e constituem ecossistemas característicos, com o estabelecimento de relações específicas com o solo, água, nutrientes, fauna e outros componentes ambientais.

O conceito de floresta urbana ganhou significado na América do Norte e na Europa, onde é utilizado para se referir ao conjunto da vegetação arbórea presente no espaço urbano (BADIRU et al., 2005). Entretanto, no Brasil, país onde os primeiros centros urbanos se desenvolveram sobre áreas de floresta atlântica, o termo é atribuído a remanescentes florestais que resistiram ao avanço das cidades, sendo englobados por essas. As florestas urbanas são formações florestais em geral encontradas em áreas de encostas ou em margens de córregos e sangas.

No processo histórico de produção do espaço e desenvolvimento das cidades no Rio Grande do Sul, a paisagem original apresentava formações florestais que podem ser divididas de acordo com Teixeira et al., (1986), em florestas ombrófilas e estacionais, além de áreas com formações pioneiras e restingas, divididas de acordo com as variações florístico-fisionômicas existentes em cada região.

Estudos paleopalinológicos recentes (BEHLING et al., 2005) apontam que mudanças climáticas ocorridas durante o holoceno, possibilitaram o avanço de florestas oriundas da região tropical da América sobre áreas campestres do Brasil meridional. Rambo (1961) já havia constatado a substituição das áreas campestres no Sul do Brasil e descrito as rotas de migração das florestas. $\mathrm{O}$ autor identificou os corredores por onde teriam migrado as espécies, sendo essas provenientes de dois elementos distintos, o primeiro oriundo das Bacias do Paraná-Uruguai, caracterizado como elemento estacional, e o segundo, advindo pelo corredor atlântico, com espécies características de clima ombrófilo. Posteriormente, Jarenkow \& Waechter (2001) ampliaram essa discussão identificando a contribuição de cada elemento em uma área de floresta estacional na região central do estado.

De modo mais recente, fragmentos florestais maiores e mais conservados tem sofrido influência direta das ações antrópicas que, conforme a cultura, ao longo do processo histórico inserem na paisagem diferentes espécies vegetais provenientes de diversas regiões naturais do mundo (ALVAREZ, 2004). Muitas dessas espécies mostram-se agressivas e acabam invadindo ambientes naturais, onde passam a ocupar o espaço de espécies nativas e causar alterações nos processos ecológicos estabelecidos (ZALBA, 2006). 
O diagnóstico da estrutura e situação da vegetação urbana é necessário a medida que se deseja realizar o manejo ou implantação de áreas verdes, bem como para a elaboração de plano diretor do município (ALVAREZ, 2004). A política de conservação de remanescentes florestais, e sua conversão legal em florestas urbanas são importantes, uma vez que estas formações representam testemunhos da história natural e sua manutenção constitui um legado as futuras gerações.

Partindo do levantamento e descrição do componente arbóreo em remanescentes florestais inseridos na paisagem urbana de Cachoeira do Sul, o presente estudo teve por objetivo identificar padrões florísticos, ecológicos e fitogeográficos desses fragmentos e, em escala local, identificar o grau de conservação e diversidade, fornecendo subsídios para futuros projetos de conservação, manejo e educação ambiental.

\section{Procedimentos Metodológicos}

\section{1 Área do estudo}

A cidade de Cachoeira do Sul está localizada na região fisiográfica denominada Depressão Central do Rio Grande do Sul, à margem do Rio Jacuí ( $30^{\circ} 02.06^{\prime} \mathrm{S}$ $\left.52^{\circ} 54.04^{\prime} \mathrm{W}\right)$, distante $173 \mathrm{Km}$ a oeste de Porto Alegre. O município apresenta população de 83.827 habitantes, destes 71.700 residem na área urbana, distribuídos em 34.639 domicílios. Entretanto, Cachoeira do Sul já contabilizou mais de 90.000 habitantes no início dos anos sessenta. Essa dinâmica negativa nos números demográficos é explicada por emancipações de distritos, sucessivas crises no setor produtivo, bem como fatores sócio-culturais que estimularam a emigração a partir dos anos setenta (IBGE, 2012).

Na área urbana, os solos de modo geral são profundos e bem drenados e sua morfo-estrutura está relacionada à dinâmica sedimentar do Rio Jacuí (JUSTUS et al., 1986). Suas cotas altimétricas encontram-se, aproximadamente, entre $26 \mathrm{~m}$ e $120 \mathrm{~m}$ de altitude, com relevo levemente ondulado.

O clima na região é considerado subtropical úmido, sem período seco definido, do tipo Cfa, segundo a classificação de Köppen. Estima-se precipitação média em torno de 1.594 mm.ano-1 (IPAGRO, 1992).

A temperatura média anual é de $19,2^{\circ} \mathrm{C}$, sendo a média do mês mais quente superior a $24^{\circ} \mathrm{C}$ e a média do mês mais frio em torno de $13{ }^{\circ} \mathrm{C}$.

\subsection{Vegetação}

O município apresenta em seu território a ocorrência dos três "grandes domínios geológicos da região Sul do Brasil", são eles: a cobertura sedimentar cenozóica (depósitos dos rios Jacuí, Vacacaí e afluentes), o planalto sul da bacia sedimentar do Paraná; ao
Norte os derrames basálticos e sedimentos cretáceos, e os terrenos pré-cambrianos ao Sul (escudo-sul-rio-grandense, ou Serra do Sudeste) ROHDE (1998). A planície do Jacuí, onde se encontra a cidade, recebe afluentes que trazem de cada lado do rio sedimentos distintos em sua origem e composição.

A paisagem onde está inserido o município de Cachoeira do Sul, por abranger diferentes formações geomorfológicas, apresenta uma vegetação rica e diversificada. A ocorrência de campos naturais (estepe-savana) nessa região representa o limite setentrional do bioma pampa. A planície sedimentar é cortada por diversos rios, que apresentam em suas margens matas de galeria classificadas como Floresta Estacional Decídua, ou ainda, Floresta Aluvial. Nas planícies de inundação, antes destas serem drenadas para a cultura do arroz, ocorriam banhados e lagoas que formavam juntamente com a calha principal do Rio Jacuí um sistema hídrico maior.

Ao Sul do município, nos tabuleiros da Serra do Sudeste, a vegetação natural é heterogênea e apresenta regiões de ecótono, caracterizado por áreas de tensão ecológica e savanas com predomínio de espécies pioneiras. Além disso, o mosaico fitofisionômico na Serra do Sudeste, é condicionado especialmente por suas condições edáficas (TEIXEIRA et al., 1986).

Ao Norte do município na borda do Planalto Sul-Brasileiro, ocorrem as "Florestas de Encosta da Serra Geral", que apresentam espécies arbóreas oriundas das formações florestais do Alto Uruguai e espécies provenientes da Mata Atlântica (RAMBO, 1961), que migraram para o Sul do continente ao término da última glaciação, durante o holoceno (BEHLING et al., 2005).

Maluf et al. (1994), no Mapa da Vegetação do Rio Grande do Sul, apontam três diferentes áreas de vegetação no município: região da savana (gramínio-lenhosa) ao Sul; áreas de tensão ecológica, na porção central do município e próximo a sede; e floresta estacional decidual, no centro-norte e nas margens dos afluentes do Jacuí.

As Florestas Estacionais que, originalmente, acompanhavam a calha do rio Jacuí e afluentes, hoje encontram-se drasticamente reduzidas. No entanto, alguns estudos em remanescentes florestais da região apontam que ainda existe significativo grau de diversidade e riqueza de espécies (ARAUJO et al., 2004; LINDENMAIER e BUDKE, 2006; BUDKE et al., 2007).

\subsection{Coleta e análise dos dados}

Os trabalhos de campo para coleta dos dados foram realizados entre novembro de 2011 e outubro de 2012. Com auxílio de sensoriamento remoto, foi possível a localização das áreas de remanescentes florestais no espaço urbano de Cachoeira do Sul (Figura 1). 
Para amostragem da vegetação foram demarcadas no interior dos remanescentes florestais parcelas de $10 \mathrm{~m} \times 10 \mathrm{~m}\left(100 \mathrm{~m}^{2}\right)$, onde foram inventariados os indivíduos arbóreos vivos e mortos ainda em pé, com perímetro mínimo $\geq$ a $10 \mathrm{~cm}$ a $1,30 \mathrm{~m}$ do solo. A suficiência amostral foi alcançada a partir da estabilização da curva amostral. O número de unidades amostrais em cada área de floresta variou conforme as dimensões do fragmento, sendo ao todo 52 parcelas inventariadas, totalizando $5.200 \mathrm{~m}^{2}$ de florestas urbanas estudadas na cidade de Cachoeira do Sul. Realizaram-se trilhas dentro das áreas florestadas a fim de identificar espécies não registradas dentro das unidades amostrais.

As espécies mais comuns e frequentes foram identificadas in loco, as demais identificações foram obtidas por meio de bibliografia, comparação com material de herbáreo ou consulta a especialistas. A classificação das famílias botânicas seguiu as orientações do Angiosperm Phylogeny Group (APG III, 2009).

A diversidade arbórea foi estimada utilizando os dados da frequência de indivíduos por espécie, e os Índices de Diversidade de Shannon $\left(\mathrm{H}^{\prime}\right)$ e Equabilidade de Pielou ( $\mathrm{J}^{\prime}$ ) foram obtidos com auxílio do aplicativo PAST ver. 1.37, 2005.

Para avaliação do estádio sucessional dos remanescentes florestais, as espécies foram agrupadas em categorias ecológicas de acordo com: a) padrões de comportamento na dinâmica de sucessão em pioneiras, secundárias iniciais, secundárias tardias e clímaces (MACIEL et al., 2003); b) porte dos indivíduos adultos, sendo divididos em indivíduos de sub-bosque, indivíduos de porte médio e indivíduos emergentes; c) porte dos indivíduos adultos, sendo divididos em indivíduos de sub-bosque, indivíduos de porte médio e indivíduos emergentes; d) estratégias de dispersão, sendo divididas em zoocóricas, anemocóricas e autocóricas, de acordo com a morfologia dos frutos e/ou sementes apresentadas (VAN DER PIJL,1982). Foram consideradas, ainda, a estratégia de dispersão hidrocórica, em virtude da presença de corpos de água junto aos fragmentos, e a estratégia antropocórica, que se refere às espécies com dispersão direta oriunda de atividades humanas.

Quanto às rotas migratórias, as espécies foram agrupadas de acordo com a proposta de Jarenkow e Waechter (2001), dividindo as espécies em três grupos: procedentes do corredor atlântico (ATL); oriundas das bacias do Paraná-Uruguai (BPU), e espécies de ampla distribuição nas formações florestais (EAD). Tal classificação baseou- se na literatura específica da área (RAMBO, 1961; KLEIN, 1972; 1984; REITZ et al., 1983; JARENKOW e WAECHTER, 2001; BUDKE et al., 2004; LINDENMAIER e BUDKE, 2006) e consulta a especialistas.

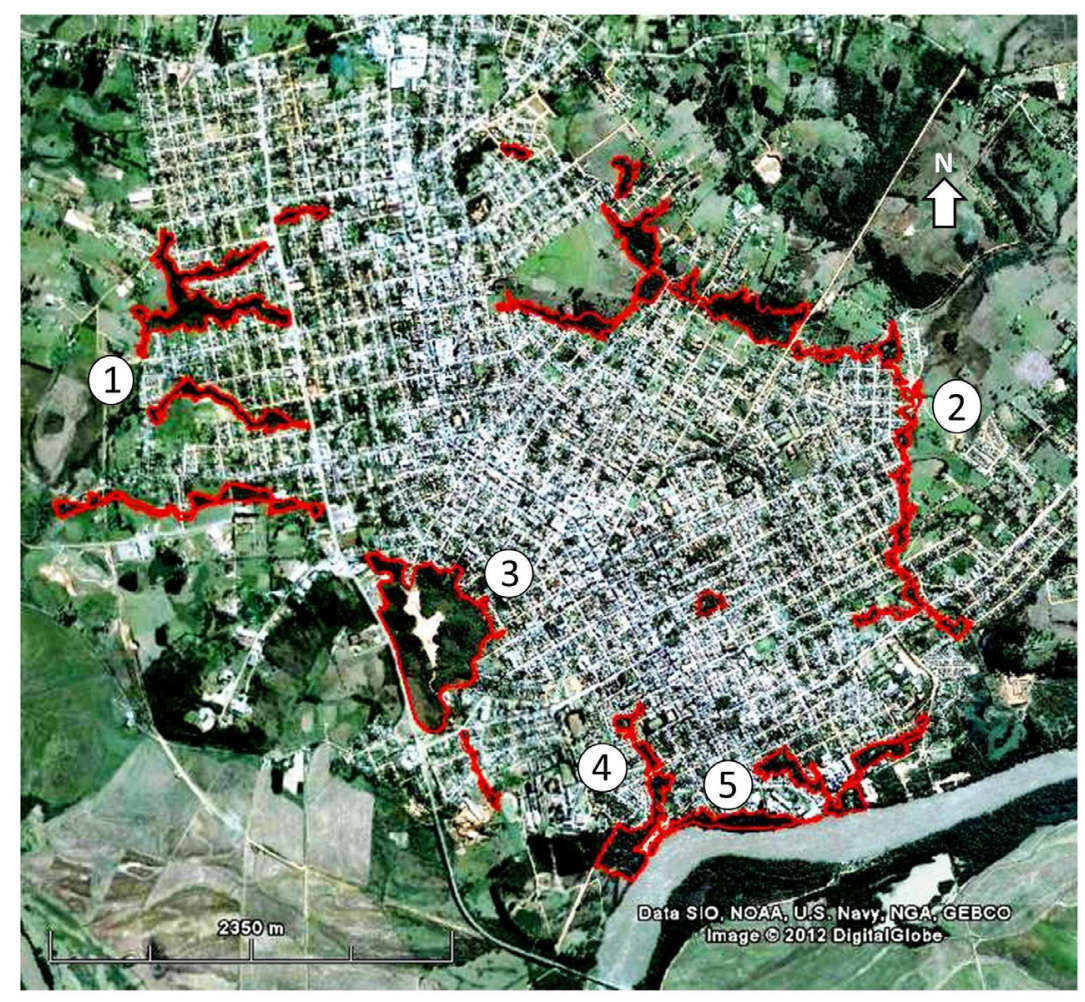

Figura 1. Imagem aérea com a localização das florestas urbanas na paisagem de Cachoeira do Sul-RS. As linhas em vermelho indicam o perímetro dos remanescentes florestais. 1- Sangas do Oeste; 2- Arroio Amorim; 3- Morro da Cruz; 4- Sanga da Inês; 5- Mata Ciliar do Rio Jacuí.

Fonte: Adaptada de Google Earth ${ }^{\mathrm{TM}}$ Mapping Service, 2012. 


\section{Resultados e Discussão}

As florestas urbanas em Cachoeira do Sul são remanescentes de formações que, originalmente, acompanhavam cursos de água (Sanga da Inês, Sangas do Oeste, Bacia do Arroio Amorim) e área de morros e encostas (Morro da Cruz). A vegetação ocorrente no Jardim Botânico, na área central da cidade, embora se enquadre no conceito de floresta urbana, não foi considerada nos cálculos deste estudo, em virtude da presença de um elevado número de espécies exóticas ali cultivadas.

Neste estudo, foram inventariadas $5.200 \mathrm{~m}^{2}$ de florestas urbanas, sendo observada a presença de 709 indivíduos arbóreos, pertencentes a 82 espécies e distribuídas em 34 famílias botânicas (Tabela 1).

A riqueza de espécies identificadas nos rema- nescentes pode ser considerada alta quando comparada a outros estudos realizados na bacia do rio Jacuí, em remanescentes maiores, contíguos e relativamente mais conservados (LINDENMAIER e BUDKE, 2006; BUDKE et al., 2007; ARAÚJO et al., 2004). Entretanto, 19,5\% dos táxons registrados nos fragmentos (16 spp.) eram exóticos, espécies cultivadas em ambientes urbanos e rurais que potencialmente agem como invasoras de comunidades florestais.

Os fragmentos florestais urbanos em Cachoeira do Sul, de modo geral, apresentaram considerável diversidade arbórea se comparados com a diversidade obtida em outros estudos realizados em florestas da região. Neste estudo, os remanescentes na Bacia do Amorim destacaram- se quanto à diversidade, sendo observado índice de Shannon de $\mathrm{H}^{\prime}$ 3,82 nats/ind. e Equabilidade de Pielou de 0,92 J'. O menor índice foi

Tabela 1. Espécies arbóreas registradas nas florestas urbanas de Cachoeira do Sul (RS) dispostas em ordem alfabética por famílias. $F A=$ frequência absoluta. $F R=$ frequência relativa. $C G=$ contingente geográfico, sendo EAD= espécies ampla distribuição, $\mathrm{BPU}=$ espécies provenientes da bacia Paraná/ Uruguai, $\mathrm{ATL}=$ espécies oriundas do corredor atlântico, $\mathrm{EXT}=$ espécies exótico/invasoras. $\mathrm{CE}=$ categorias ecológicas, sendo: $\mathrm{P}=$ pioneira; $\mathrm{Si}=$ secundária inicial; $\mathrm{St}=$ secundária tardia; $\mathrm{C}=$ clímace; $\mathrm{In}=$ invasora; $\tilde{\mathrm{n}}=$ sem informação. $S=$ sub-bosque; $M=$ médio porte; $E=$ emergente. $Z$ oo= zoocoria; Ane= anemocoria; Aut= autocoria; Hid= hidrocoria; Ant= antropocoria; ñ= sem informação

\begin{tabular}{|c|c|c|c|c|}
\hline Família/espécie & FA & FR\% & CG & $\mathbf{C E}$ \\
\hline \multicolumn{5}{|l|}{ Anarcadiaceae } \\
\hline Lithraea brasiliensis Marchand. & 7 & 0,98 & EAD & P-M-Zoo \\
\hline Schinus molle L. & 1 & 0,14 & EAD & P-M-Zoo \\
\hline Schinus terebinthifolius Raddi & 1 & 0,14 & EAD & P-M-Zoo \\
\hline \multicolumn{5}{|l|}{ Annonaceae } \\
\hline Annona neosalicifolia $\mathrm{H}$. Rainer & 4 & 0,56 & BPU & Si-M-Zoo \\
\hline \multicolumn{5}{|l|}{ Apocynaceae } \\
\hline Tabernaemontana catharinensis A. DC. & 1 & 0,14 & EAD & P-M-ñ \\
\hline \multicolumn{5}{|l|}{ Arecaceae } \\
\hline Butia capitata (Mart.) Becc. & 1 & 0,14 & ATL & St-M-Zoo \\
\hline $\begin{array}{l}\text { Syagrus romanzoffiana (Cham.) } \\
\text { Glassman }\end{array}$ & 2 & 0,28 & EAD & St-E-Zoo \\
\hline \multicolumn{5}{|l|}{ Asteraceae } \\
\hline Gochnatia polymorpha (Less.) Cabrera & 4 & 0,56 & EAD & P-M-Ane \\
\hline \multicolumn{5}{|l|}{ Bignoniaceae } \\
\hline $\begin{array}{l}\text { Handroanthus heptaphyllus (Vell.) } \\
\text { ex.Toledo }\end{array}$ & 2 & 0,28 & BPU & St-E-Ane \\
\hline Jacaranda mimosifolia D. Don & 2 & 0,28 & EXT & St-E-Ane \\
\hline Tecoma stans (L.) & 5 & 0,70 & EXT & P-S-ñ \\
\hline \multicolumn{5}{|l|}{ Boraginaceae } \\
\hline $\begin{array}{l}\text { Cordia americana (L.) Gottshling \& } \\
\text { J.E.Mill. }\end{array}$ & 7 & 0,98 & EAD & St-E-Ane \\
\hline \multicolumn{5}{|l|}{ Cannabaceae } \\
\hline Trema micrantha (L.) Blume & 12 & 1,70 & EAD & Si-M-Zoo \\
\hline
\end{tabular}

continua... 
Tabela 1. continuação...

\begin{tabular}{|c|c|c|c|c|}
\hline Família/espécie & FA & FR\% & CG & $\mathbf{C E}$ \\
\hline \multicolumn{5}{|l|}{ Combretaceae } \\
\hline Terminalia australis Cambess. & 2 & 0,28 & EAD & Si-S-ñ \\
\hline \multicolumn{5}{|l|}{ Ebenaceae } \\
\hline Diospyros inconstans Jacq. & 3 & 0,42 & EAD & Si-M-Zoo \\
\hline \multicolumn{5}{|l|}{ Euphorbiaceae } \\
\hline $\begin{array}{l}\text { Actinostemon concolor (Spreng.) Müll. } \\
\text { Arg. }\end{array}$ & 24 & 3,38 & EAD & St-S-Aut \\
\hline Ricinus sp. & 5 & 0,70 & EXT & P-S-ñ \\
\hline Sapium glandulosum (L.) Morong & 1 & 0,14 & EAD & P-S-ñ \\
\hline Sebastiania brasiliensis Spreng. & 1 & 0,14 & EAD & St-M-Aut/Hid \\
\hline $\begin{array}{l}\text { Sebastiana commersoniana (Baill.) } \\
\text { Smith \& Downs }\end{array}$ & 44 & 6,20 & EAD & Si-M-Aut/Hid \\
\hline \multicolumn{5}{|l|}{ Fabaceae } \\
\hline $\begin{array}{l}\text { Albizia edwallii (Hoehne) Barneby \& } \\
\text { J.Grimes }\end{array}$ & 2 & 0,28 & BPU & St-E-Ane \\
\hline Apuleia leiocarpa (Vogel) J.F.Macbr. & 4 & 0,56 & $\mathrm{BPU}$ & St-E-Ane \\
\hline Ateleia glazioviana Baill. & 2 & 0,28 & $\mathrm{BPU}$ & P-M-Ane \\
\hline Calliandra tweediei Benth. & 2 & 0,28 & $\mathrm{BPU}$ & Si-S-Aut \\
\hline $\begin{array}{l}\text { Enterolobium contortisiliquum (Vell.) } \\
\text { Morong }\end{array}$ & 7 & 0,98 & EAD & Si-E-Zoo \\
\hline Erythrina crista-galli $\mathrm{L}$. & 1 & 0,14 & EAD & Si-M-Aut/Hid \\
\hline Mimosa bimucronata (DC.) Kuntze & 41 & 5,78 & EAD & $\mathrm{P}-\mathrm{M}-\tilde{\mathrm{n}}$ \\
\hline Inga marginata Kunth & 11 & 1,55 & EAD & Si-M-Zoo \\
\hline Inga vera Willd. & 52 & 7,33 & EAD & P-M-Zoo/Hid \\
\hline Paraptadenia rigida (Benth.) Brenan. & 14 & 1,97 & EAD & Si-E-Ane \\
\hline \multicolumn{5}{|l|}{ Lamiaceae } \\
\hline $\begin{array}{l}\text { Vitex megapotamica (Spreng.) } \\
\text { Moldenke }\end{array}$ & 8 & 1,12 & EAD & Si-M-Zoo \\
\hline \multicolumn{5}{|l|}{ Lauraceae } \\
\hline Nectandra megapotamica (Spreng.) Mez & 40 & 5,64 & EAD & Si-M-Zoo \\
\hline Ocotea pulchella (Ness) Mez & 2 & 0,28 & EAD & St-M-Zoo \\
\hline Persea americana Mill. & 5 & 0,70 & EXT & $\tilde{\mathrm{n}}-\mathrm{E}-\mathrm{Ant}$ \\
\hline \multicolumn{5}{|l|}{ Malvaceae } \\
\hline Ceiba speciosa (A.St.-Hil.) Ravenna & 5 & 0,70 & $\mathrm{BPU}$ & Si-E-Ane \\
\hline Luehea divaricata Mart. & 25 & 3,52 & EAD & Si-E-Ane \\
\hline \multicolumn{5}{|l|}{ Meliaceae } \\
\hline Cedrela fissilis Vell. & 5 & 0,70 & EAD & Si-E-Ane \\
\hline Trichilia claussenii C.DC. & 1 & 0,14 & EAD & Si-M-Zoo \\
\hline Trichilia elegans A. Juss. & 4 & 0,56 & EAD & Si-S-Zoo \\
\hline \multicolumn{5}{|l|}{ Myrtaceae } \\
\hline Eucaliptus sp. & 1 & 0,14 & EXT & In-E-Ane \\
\hline Eugenia sp. & 3 & 0,42 & & Si-S-Zoo \\
\hline Eugenia hiemalis Cambess. & 1 & 0,14 & ATL & Si-S-Zoo \\
\hline Eugenia involucrta DC. & 1 & 0,14 & EAD & C-M-Zoo \\
\hline Eugenia uniflora L. & 10 & 1,41 & EAD & P-M-Zoo \\
\hline Myrciaria tenella (DC.) O. Berg & 1 & 0,14 & $\mathrm{BPU}$ & C-S-Zoo \\
\hline
\end{tabular}


Tabela 1. continuação...

\begin{tabular}{|c|c|c|c|c|}
\hline Família/espécie & FA & FR\% & CG & $\mathbf{C E}$ \\
\hline $\begin{array}{l}\text { Myrcianthes pungens (O.Berg) D. } \\
\text { Legrand }\end{array}$ & 1 & 0,14 & EAD & St-M-Zoo \\
\hline Psidium cattleyanum Sabine & 1 & 0,14 & ATL & St-S-Zoo \\
\hline Psidium guajava $\mathrm{L}$. & 4 & 0,56 & EXT & In-M-Zoo \\
\hline \multicolumn{5}{|l|}{ Moraceae } \\
\hline Ficus cestrifolia Schott & 1 & 0,14 & ATL & C-E-Zoo \\
\hline Ficus luschnathiana (Miq.) Miq. & 8 & 1,12 & EAD & St-E-Zoo \\
\hline Morus nigra L. & 20 & 2,82 & EXT & In-M-Zoo \\
\hline $\begin{array}{l}\text { Sorocea bonplandii (Baill.) W.C. Burger, } \\
\text { Lanj. \& Wess. Boer }\end{array}$ & 19 & 2,67 & EAD & St-S-Zoo \\
\hline \multicolumn{5}{|l|}{ Musaceae } \\
\hline Musa $\mathrm{x}$ paradisiaca $\mathrm{L}$. & 2 & 0,28 & EXT & $\tilde{\mathrm{n}}-\mathrm{S}-\mathrm{Ant}$ \\
\hline \multicolumn{5}{|l|}{ Oleaceae } \\
\hline Ligustrum lucidum W. T. Aiton & 1 & 0,14 & EXT & In-M-Ant \\
\hline \multicolumn{5}{|l|}{ Pinaceae } \\
\hline Pinus taeda $\mathrm{L}$. & 1 & 0,14 & EXT & In-E-Ane \\
\hline \multicolumn{5}{|l|}{ Phyllanthaceae } \\
\hline $\begin{array}{l}\text { Phyllanthus sellowianus (Klotzsch) } \\
\text { Müll.Arg. }\end{array}$ & 15 & 2,11 & EAD & Si-S-Aut/Hid \\
\hline \multicolumn{5}{|l|}{ Poaceae } \\
\hline Bambusa sp. & 10 & 1,41 & EXT & ñ-M-Ant \\
\hline \multicolumn{5}{|l|}{ Polygonaceae } \\
\hline Ruprechtia laxiflora Meisn. & 1 & 0,14 & EAD & Si-E-Ane \\
\hline \multicolumn{5}{|l|}{ Primulaceae } \\
\hline Myrsine sp. & 13 & 1,83 & EAD & Si-S-Zoo \\
\hline \multicolumn{5}{|l|}{ Rhamnaceae } \\
\hline Hovenia dulcis Thunb. & 7 & 0,98 & EXT & In-E-Zoo \\
\hline \multicolumn{5}{|l|}{ Rosaceae } \\
\hline Eriobotrya japonica (Thunb.) Lindl. & 7 & 0,98 & EXT & In-M-Zoo \\
\hline Prunus myrtifolia (L.) Urb. & 7 & 0,98 & EAD & Si-M-Zoo \\
\hline \multicolumn{5}{|l|}{ Rubiaceae } \\
\hline Chomelia obtusa Cham. \& Schultdl. & 3 & 0,42 & EAD & Si-S-Zoo \\
\hline $\begin{array}{l}\text { Faramea montevidensis (Cham. \& } \\
\text { Schltdl.) DC. }\end{array}$ & 8 & 1,12 & ATL & Si-S-Zoo \\
\hline \multicolumn{5}{|l|}{ Rutaceae } \\
\hline Citrus sp. & 8 & 1,12 & EXT & In-S-Zoo \\
\hline Helietta apiculata Benth. & 3 & 0,42 & $\mathrm{BPU}$ & Si-E-Ane \\
\hline Zanthoxylum fagara (L.) Sarg. & 9 & 1,26 & EAD & P-M-Zoo \\
\hline \multicolumn{5}{|l|}{ Salicaceae } \\
\hline Banara tomentosa Clos & 1 & 0,14 & $\mathrm{BPU}$ & St-M-Zoo \\
\hline Casearia decandra Jacq. & 2 & 0,28 & EAD & Si-M-Zoo \\
\hline Casearia sylvestris Sw. & 74 & 10,43 & EAD & Si-M-Zoo \\
\hline Salix humboldtiana Willd. & 6 & 0,84 & EAD & Si-E-Ane/Hid \\
\hline Populus alba L. & 1 & 0,14 & EXT & In-E-ñ \\
\hline
\end{tabular}


Tabela 1. continuação..

\begin{tabular}{|l|c|c|c|c|}
\hline Família/espécie & FA & FR\% & CG & CE \\
\hline Sapindaceae & & & & \\
\hline $\begin{array}{l}\text { Allophylus edulis (A. St.-Hil., Cambess. } \\
\text { \& A. Juss.) Radlk. }\end{array}$ & 32 & 4,51 & EAD & Si-M-Zoo \\
\hline Cupania vernalis Cambess. & 26 & 3,66 & EAD & St-E-Zoo \\
\hline Matayba elaeagnoides Radlk. & 14 & 1,97 & EAD & St-E-Zoo \\
\hline Sapotaceae & & & & \\
\hline $\begin{array}{l}\text { Chrysophyllum gonocarpum (Mart. \& } \\
\text { Eichler ex Miq.) Engl. }\end{array}$ & 2 & 0,28 & EAD & St-M-Zoo \\
\hline $\begin{array}{l}\text { Chrysophyllum marginatum (Hook. \& } \\
\text { Arn.) Radlk. }\end{array}$ & 1 & 0,14 & EAD & St-M-Zoo \\
\hline Pouteria gardneriana (DC.) Radlk. & 4 & 0,56 & BPU & St-M-Zoo \\
\hline $\begin{array}{l}\text { Solanaceae } \\
\text { Brugmansia suaveolens (Humb. \& } \\
\text { Bonpl. ex Willd.) Bercht. \& C. Presl }\end{array}$ & 2 & 0,28 & EXT & In-S-ñ \\
\hline $\begin{array}{l}\text { Brunfelsia cf. australis } \text { Benth. } \\
\text { Solanum mauricianum } \text { Scop. }\end{array}$ & 1 & 0,14 & BPU & St-S-Zoo \\
\hline Urticaceae & & 1,97 & EAD & P-S-Zoo \\
\hline Urera baccifera (L.) Gaudich & 1 & 0,14 & EAD & Si-S-Zoo \\
\hline
\end{tabular}

registrado para as Sangas do Oeste, $\mathrm{H}^{\prime}$ 3,0 nats/ind. e 0,94 J'. Os valores registrados para os índices de Shannon podem ser explicados pelo elevado número de espécies e pela relativa equidade na frequência de indivíduos (Figura 2). Contudo, ressalta-se que a adição de espécies e indivíduos exótico/invasores nos fragmentos contribuiu significativamente para a elevação do índice de diversidade de Shannon.

O remanescente florestal presente no Morro da Cruz, área de encosta, apresentou espécies diferentes das encontradas em outros fragmentos que sofrem influencia direta dos cursos de água, registrando um índice de diversidade de valor intermediário, $\mathrm{H}^{\prime} 3,68$ nats/ind. e J' 0,95 nats/ind. Na mata ciliar do Rio Jacuí, os fragmentos estudados apresentaram baixa riqueza de espécies, com predominância de Inga vera, contudo, o índice de diversidade registrou nível intermediário, $\mathrm{H}^{\prime} 3,19$ nats/ind. e J' 0,94 nats/ind. (Figura 2).

Quanto à distribuição geográfica das espécies que compõem as florestas urbanas de Cachoeira do Sul, verificou-se que 59,5\% das essências vegetais apresentam ampla distribuição nas formações florestais do Sul do Brasil, seguida de espécies exótico/invasoras (20,7\%). Espécies atlânticas perfizeram somente $6,2 \%$ do total da área estudada. Quando relacionada à abundância de indivíduos nas áreas, constatou-se uma predominância maior de espécies de ampla distribuição, com $82,4 \%$ do número total de indivíduos amostrados. Os indivíduos pertencentes às espécies exóticas registraram $11,5 \%$ do total, seguidos daqueles provenientes da bacia Paraná/Uruguai $(4,4 \%)$ e dos elementos atlânticos (1,7\%).
De acordo com os registros de campo e referências sobre características ecológicas e sucessionais, constatou-se que $37 \%$ das espécies presentes nas florestas estudadas são secundárias iniciais. As secundárias tardias registraram $25,9 \%$ e as pioneiras $16 \%$. Espécies clímaces apresentaram baixa abundância $(3,7 \%)$ e as invasoras perfizeram $13,6 \%$ do total. Na relação indivíduo/espécie, o quadro anterior sofre pouca alteração, com $50 \%$ de indivíduos secundários iniciais, $22,2 \%$ de indivíduos exóticos e 17,6\% de secundários tardios (Tabela 2).

Nas florestas estudadas, a maioria das espécies e indivíduos apresentaram porte médio, ou seja, vegetais que atingem a parte intermediária do estrato vertical das comunidades florestais (Tabela 2).

A avaliação das estratégias de dispersão demonstrou que $58,5 \%$ das espécies apresentam dispersão zoocórica, seguidas de espécies anemocóricas. Na relação modo de dispersão e abundância de indivíduos também prevaleceu as espécies zoocóricas, seguido de indivíduos hidrocóricos, e anemocóricos. A análise das estratégias de dispersão em meio urbano demonstra certa complexidade, especialmente em razão das ações antrópicas e pelo fato de muitas espécies apresentarem mais de um modo de dispersão.

\section{Conclusões}

A riqueza de espécies nas florestas urbanas em Cachoeira do Sul é considera alta quando comparada a outros estudos em remanescentes florestais maiores, 

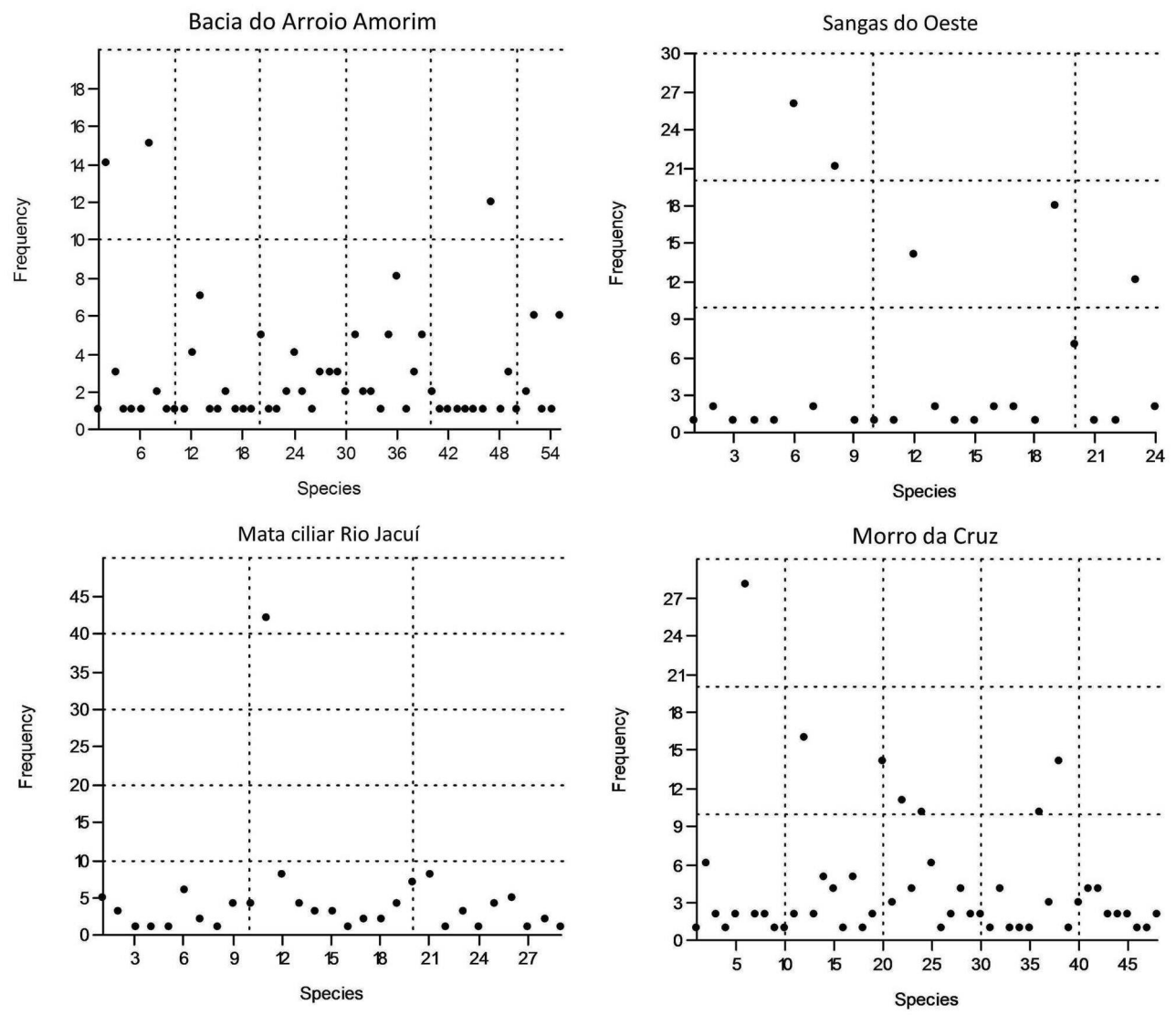

Figura 2. Abundância de indivíduos por espécie nos diferentes fragmentos de florestas urbanas estudadas em Cachoeira do Sul/ RS, 2012

Tabela 2. Proporção de espécies e indivíduos em diferentes categorias ecológicas nas florestas urbanas de Cachoeira do Sul.

\begin{tabular}{l|c|c}
\hline \multicolumn{1}{c|}{ Categoria ecológica } & \% de espécies & \% de indivíduos \\
\hline Estratégia de dispersão & 58,5 & 57,2 \\
Zoocoria & 18,3 & 11,8 \\
Anemocoria & 4,8 & 0,56 \\
Autocoria & 7,3 & 16,8 \\
Hidrocoria $^{1}$ & 4,8 & 2,5 \\
Antropocoria $^{2}$ & 9,7 & 8,2 \\
Indefinida $^{3}(\tilde{\mathrm{n}})$ & & \\
Estádio sucessional & 16,0 & 22,2 \\
Pioneira & 37 & 50 \\
Secundária & 25,9 & 17,6 \\
inicial & 3,7 & 0,42 \\
Secundária tardia & 13,6 & 7,3 \\
Clímace & 3,7 & 2,3 \\
Invasora & & \\
Estratificação/porte & 26,8 & 19,2 \\
Sub-bosque & 45,1 & 59,8 \\
Médio & 28,0 & 20,9 \\
Emergente & & \\
\hline
\end{tabular}

${ }^{1}$ Algumas espécies embora apresentem propágulos adaptados a um modo de dispersão, tem nos cursos de água significativo vetor de propagação. Cada estratégia de dispersão foi quantificada de forma integral, mesmo as espécies apresentando mais de um modo de dispersão.

${ }^{2}$ Espécies reconhecidamente dispersas por atividades antrópicas.

${ }^{3}$ Espécies cujo modo de dispersão é desconhecido ou não foram localizadas na literatura. 
presentes na região. Os fragmentos estudados apresentaram elevado caráter de diversidade arbórea, o que se deve a alta riqueza florística e a relativa equidade na frequência de indivíduos.

A maioria das espécies e indivíduos arbóreos presentes nas florestas urbanas de Cachoeira do Sul apresentam ampla distribuição nas formações florestais do Sul do Brasil, ocorrendo juntamente em florestas do Alto Uruguai e Corredor Atlântico.

As florestas urbanas encontram-se em um estádio de sucessão considerado secundário inicial, com presença majoritária de espécies e indivíduos com características iniciais, pioneiras e tardias.

Os remanescentes florestais urbanos apresentam ainda elevado número de espécies e indivíduos exótico/invasores. Esse aporte de espécies constituiu um considerável incremento quantitativo à riqueza total, elevando ainda a diversidade arbórea específica. Entretanto, ressalta-se que a presença dessas espécies mascara o valor de riqueza e diversidade, uma vez que em termos funcionais as florestas perdem em potencial ecológico.

Através das observações diretas em campo bem como análise dos dados oriundos das categorias ecológicas, pode-se considerar os fragmentos florestais urbanos de Cachoeira do Sul como remanescentes vulneráveis, formados principalmente por espécies arbóreas robustas, resistentes às pressões da urbanização e aos constantes distúrbios, fenômeno inerente ao avanço das cidades.

\section{Referências}

ALVAREZ, I. A. Qualidade do espaço verde urbano: uma proposta de índice de avaliação. 2004. 240 f. Tese (Doutorado em Agronomia) Escola Superior de Agricultura "Luiz de Queiroz", Universidade de São Paulo - Piracicaba, 2004.

APG III. An update of the Angiosperm Phylogeny Group classification for the orders and families of flowering plants: APG III. Botanical Journal of Linnean Society, n. 161, p. 128-131, 2009.

ARAUJO, M.M.; LONGHI, S.J.; BRENA, D.A.; BARROS, P.L.C. \& FRANCO, S. Análise de agrupamento da vegetação de um fragmento de floresta estacional decidual aluvial. Cachoeira do Sul, RS, Brasil. Ciência Florestal, n. 14, p. 133-147, 2004.

BADIRU, A.S.; PIRES, M.A.; RODRIGUEZ, A.C.M. Método para a classificação tipológica da floresta urbana visando o planejamento e a gestão das cidades. In: XII SIMPÓSIO BRASILEIRO DE SENSORIAMENTO REMOTO, 2005, Goiânia, Brasil, INPE, Anais... Goiânia, 2005, p. 1427-1433.

BEHLING, H.; PILLAR, V.D.P. \& BAUERMANN, S.G. Late Quaternary grassland (Campos), fire and climate dynamics, studied by pollen, charcoal and multivariate analysis of the São Francisco de Assis core in western Rio Grande do Sul (southern Brazil). Review of Palaeobotany and Palynology. n. 133, p. 235-248, 2005.

BENINI, S.M. Áreas verdes públicas: a construção do conceito e a análise geográfica desses espaços no ambiente urbano. 2009. 283 f. Dissertação (Mestrado em Geografia) Presidente Prudente, 2009.

BUDKE, J.C.; GIEHL, E.L.H.; ATHAYDE, E.A.; EISINGER, S.M. \& ZÁCHIA, R.A. Florística e fitossociologia do componente arbóreo de uma floresta ribeirinha, arroio Passo das Tropas, Santa Maria, RS, Brasil. Acta Botanica Brasilica. n. 18, p. 581-589, 2004.

BUDKE, J.C., JARENKOW, J.A., OLIVEIRAFILHO, A.T. Relationships between tree component structure, topography and soils of a riverine forest, Rio Botucarai', Southern Brazil. Plant Ecology. n. 89, p. 187-200, 2007.

CAPORUSSO, D. e MATIAS, L.F. Áreas verdes urbanas: avaliação e proposta conceitual. In: Simpósio de Pós-Graduação em Geografia do Estado de São Paulo, 2008, Rio Claro. Anais... Rio Claro: UNESP, p. 71-87, 2008.

CHRISTOFOLETTI, A. Modelagem de sistemas ambientais. Editora Edgard Blucher LTDA. 1 edição, São Paulo, 1999, 236p.

DEMATTÊ, M. E. S. P. Princípio de paisagismo. Jaboticabal: Funep, 1997.

GÊISER, R. R.; OLIVEIRA, M. C. de; BRUCK, E. C.; SANTOS, J. B. DOS. Implantação de áreas verdes em grandes cidades. São Paulo: Escola Paulista de Arte e Decoração, 1976.

GOOGLE EARTH MAPPING SERVICE. Imagens de satélite da cidade de Cachoeira do Sul. 2012. Disponível em: <http://earth.google.com/intl/pt/ download.earth.html>. Acesso em: 2 out. 2012. 
IBGE: Web Site do Instituto Brasileiro de Geografia e Estatística. Disponível em: <http://www.ibge. gov.br>. Acesso em 20 jan. 2012.

IPAGRO. Atlas agroclimático do Rio Grande do Sul. Porto Alegre, Editora Pallotti, 1992.

JARENKOW, J.A. \& WAECHTER, J.L. Composição, estrutura e relações florísticas do componente arbóreo de uma floresta estacional no Rio Grande do Sul, Brasil. Revista Brasileira de Botânica. v. 24, n. 3, p. 263-272, 2001.

\section{JUSTUS J.O.; MACHADO M.L.A. \& FRANCO}

M.S.M. Geomorfologia. In: IBGE(ed),

Levantamento de Recursos Naturais (33). Instituto

Brasileiro de Geografia e Estatística, Rio de Janeiro, p. $313-404,1986$.

KLEIN, R.M. Árvores nativas da Floresta Subtropical do Alto Uruguai. Sellowia n. 24, p. 9-62, 1972.

LIMA, A. M. L.P; CAVALHEIRO, F.; NUCCI, J.C.; SOUSA, M.A.L.B.; FIALHO, N. DEL PICCHIA, P.C.D. Problemas de utilização na conceituação de termos como espaços livres, áreas verdes e correlatos. In: II CONGRESSO DE ARBORIZAÇÃO URBANA. 1994, São Luis-MA, Anais... São Luis. 1994, p 539-553.

LIMA NETO, E.M.; BIONDI, D. e ARAKI, H. Aplicação do SIG na arborização viária - Unidade amostral em Curitiba-Paraná. In: SIMPÓSIO BRASILEIRO DE CIÊNCIAS GEODÉSICAS E TECNOLOGIAS DE GEOINFORMAÇÃO. 2010, Recife. Anais... Recife, 2010, p. 01-06.

LINDENMAIER, D.S., BUDKE, J.C. Florística, diversidade e distribuição espacial das espécies arbóreas de uma floresta estacional na bacia do rio Jacuí, sul do Brasil. PESQUISAS, série Botânica. n. 57, p. 193-216, 2006.

MACIEL, M.N.M.; WATZLAWICK, L.F.; SCHOENINGER, E.R.; YAMAJI, F.M. Classificação ecológica das espécies arbóreas. Revista Acadêmica: ciências agrárias e ambientais, Curitiba, v.1, n.2, p. 69-78, abr./jun. 2003.

MAGALHAES, L.M.S. Arborização e florestas urbanas - terminologia adotada para a cobertura arbórea das cidades brasileiras. Floresta e Ambiente. Serie Tecnica. p. 23-26, 2006.
MALUF, J.R.T. et.al. Macrozoneamento agroecológico e econômico do Estado do Rio Grande do Sul. Porto Alegre: Secretaria de Agricultura e Abastecimento/Centro Nacional de Pesquisa do Trigo, v.1, 1994, 307p.

PAST. Palaeontological Statistics, ver. 1.37. Øyvind Hammer, D.A.T. Harper and P.D. Ryan. November 4, 2005.

PUGLIELLI, H.F.N. Análise da fragmentação da cobertura vegetal como subsídio ao planejamento da paisagem em áreas urbanizadas: aplicação ao bairro de Santa Felicidade, Curitiba-PR. 2008, 174 f. Dissertação (Mestrado em Geografia) UFPR, Curitiba, 2008.

RAMBO, B. Migration routes of the South Brazilian rain forest. PESQUISAS série Botânica. $\mathrm{n}$. 12, p. 1-54, 1961.

REITZ, P.; KLEIN, R.M. \& REIS, A. Projeto Madeira do Rio Grande do Sul. Sellowia. n.34/35, p. 1-525, 1983.

ROHDE, G.M. Cachoeira do Sul: uma perspectiva ambiental. Canoas: Ed. ULBRA, 1998, 268 p.

TEIXEIRA, M. B.; COURA NETO, A. B.; PASTORE, U. \& RANGEL FILHO, A. L. R. Vegetação In: Levantamento de recursos naturais (33). Rio de Janeiro, Instituto Brasileiro de Geografia e Estatística, 1986, p. 541-632.

UNFPA. Relatório do Fundo de População das Nações Unidas. 2011. Disponível em: http://www. unfpa.org.br/novo/ - Acesso em 21 nov. 2012.

VAN DER PIJL, L. 1982. Principles of dispersal in higher plants. 3rd ed. Springer Verlag, New York, 1982, 215 p.

ZALBA, S. M. Introdução às Invasões Biológicas - Conceitos e Definições. In: BRAND, K. et al. América do Sul invadida. A crescente ameaça das espécies exóticas invasoras. Cape Town: Programa Global de Espécies Invasoras - GISP, 2006, p. 4-5. 